\title{
Acetazolamide in prevention of acute mountain sickness: a double-blind controlled cross-over study
}

\author{
M K GREENE, A M KERR, I B McINTOSH, R J PRESCOTT
}

\begin{abstract}
Twenty-four amateur climbers took part in a doubleblind controlled cross-over trial of acetazolamide versus placebo for the prevention of acute mountain sickness. They climbed Kilimanjaro (5895 $\mathrm{m}$ ) and Mt Kenya (5186 $m$ ) in three weeks with five rest days between ascents. The severity of acute mountain sickness was gauged by a score derived from symptoms recorded daily by each subject. On Kilimanjaro those taking acetazolamide reached a higher altitude (11 $\mathrm{v} 4$ reached the summit) and had a lower symptom score than those taking placebo (mean $4.8 \mathrm{v} 14.3$ ). Those who had taken acetazolamide on Kilimanjaro maintained their low symptom scores while taking placebo on Mt Kenya (mean score 1.9), whereas those who had taken placebo on Kilimanjaro experienced a pronounced improvement when they took acetazolamide on Mt Kenya (mean score 2.5). Acute mountain sickness prevented one subject from completing either ascent. Acetazolamide was acceptable to 23 of the 24 subjects.
\end{abstract}

Acetazolamide is recommended as an acceptable and effective prophylactic for acute mountain sickness.

\section{Introduction}

The present popularity of short trekking holidays with rapid ascents has concentrated attention on the problem of acute

Charing Cross Hospital, London W6 8RF

M K GREENE, medical student

Royal Hospital for Sick Children, Yorkhill, Glasgow G3 8SJ

A M KERR, DCH, MRCP, registrar in paediatrics (present appointment: senior registrar

Stirling Royal Infirmary, Stirling FK8 2AU

I $\mathrm{B}$ MCINTOSH, MB, CHB, clinical assistant in geriatrics and general practitioner

Edinburgh Medical School, Edinburgh

R J PRESCOTT, MSC, PHD, senior lecturer in medical statistics mountain sickness. This is a symptom complex in which weakness, breathlessness, dizziness, and nausea impair performance and enjoyment for those who are unacclimatised and who venture over 3000 metres. It is usually mild and transient and at its worst within three days; in a few people, however, it progresses rapidly to life-threatening pulmonary or cerebral oedema. Incidence is highest when ascent is rapid and exertion great. Susceptibility has been reported greatest in the young, decreasing up to the age of $40 .^{1}$ At high altitudes, the hyperventilation which would compensate for a falling arterial oxygen is inhibited by the respiratory alkalosis which it induces. This happens chiefly during sleep and it is at that time that acetazolamide may have a beneficial effect by producing a metabolic acidosis. $^{23}$ The place of acetazolamide in the prevention of altitude sickness has been explored through decompression experiments and in several clinical trials. No trekking expedition, however, has met all the requirements of a double-blind controlled trial, and a cross-over trial has not been attempted. ${ }^{2}$ 4-8 One study ${ }^{2}$ compared the performances of five climbers on two expeditions a year apart.

We set out to meet the necessary conditions for a trial of acetazolamide during an attempt on Africa's two highest peaks by the Scout East Africa Expedition in the summer of 1980 .

\section{Methods}

The party comprised 24 British residents, including two women. None were professional sportsmen; five were medically trained. They were paired for age, sex, and likely activities, and each member of each pair was allocated at random to one of two treatment groups. Treatment group 1 received acetazolamide (sustained release $500 \mathrm{mg}$ nightly) on five nights before and during the first ascent and identically presented placebo before and during the second ascent. The treatment order was reversed for group 2 (see fig 1, which also gives expedition objectives).

An error in allocation of capsules led to the re-arrangement of two pairs; the pairs of subject 22 and subject 20 and of subject 19 and subject 21 being changed to $19 / 20$ and 21/22: the table shows the pairs actually used. The conclusions from statistical analysis are unaffected if these pairs are excluded, and they are therefore included.

The entire party travelled by air from London to Nairobi, by road to Kilimanjaro, and then on foot from $2000 \mathrm{~m}$. Kit weighing about $10 \mathrm{~kg}$ was carried. Nights were spent at the hut camps provided. 
On Mt Kenya the expedition divided into four activity groups, the participants being decided during the trek. The table gives identification numbers of subjects. Subjects 2, 3, 7, and 21 left in advance and climbed the central rock pinnacles Nelian $(5174 \mathrm{~m})$ and Batian $(5186$ $\mathrm{m}$ ); subjects $4,8,12$, and 19 , acting as support party, climbed on rock and glacier around $5000 \mathrm{~m}$; and subjects $6,16,17$, and 23 circumnavigated the central pinnacles and climbed point Lenana $(4972 \mathrm{~m})$. The remainder climbed point Lenana only. The party slept in tents and carried an average of $10 \mathrm{~kg}$ each.

Before departure the medical project was explained and full cooperation obtained. Every subject recorded each day's symptoms nightly on a card. A list of common symptoms of acute mountain sickness was printed down one side of the squared card and expedition days across the top. One tick was to be entered if a symptom was experienced on a given day. Spaces were provided for: distance walked, load carried, night altitude, metres climbed, symptoms not related to acute mountain sickness, and medication. Comments were invited. Permitted drugs for treatment were: aspirin for headache; diphenoxylate and atropine (Lomotil) for diarrhoea; temazepam and nitrazepam for sleeplessness; and chloroquine, pyrimethamine, and dapsone for malarial prophylaxis.

Scores for acute mountain sickness were calculated from symptom cards by giving one point for mild headache, loss of appetite, feeling sick, severe inappropriate weakness, dizziness, depression, irritability, drowsiness, cough, and shortness of breath walking on the flat, and three points each for severe headache, vomiting, staggering, shortness of breath at rest, and frothy spit. If severe headache or shortness of breath at rest was scored then its milder form was not. Each subject's score was calculated for days spent off the mountains and was averaged

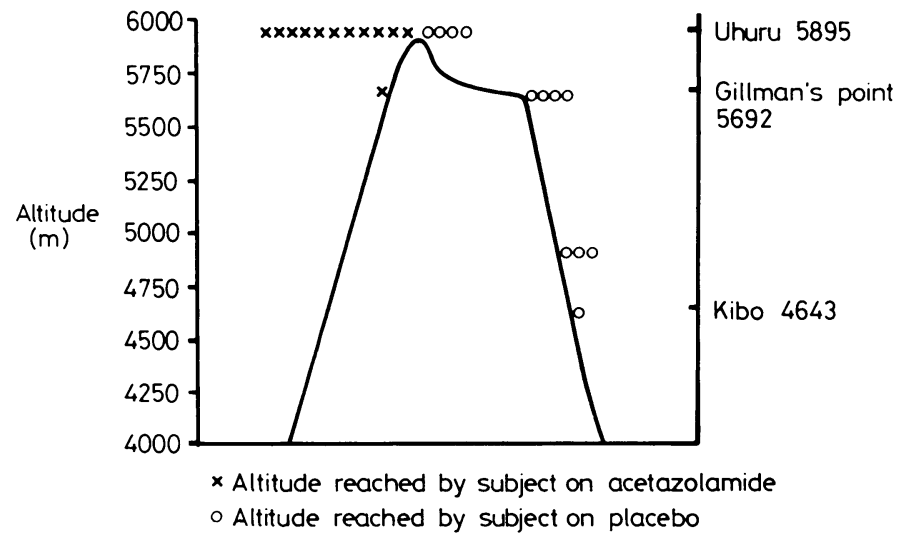

FIG 2-Altitudes reached on Kilimanjaro.

included the summit for everyone on Kilimanjaro and comparable altitudes for everyone on Mt Kenya (see fig 1).

The data do not conform to normal distributions, therefore nonparametric tests of significance (Wilcoxon and Spearman rank correlation tests) were used. The test used to examine interaction between the first and second treatment periods and ascents is based on that described by Hills and Armitage ${ }^{9}$ with an adaptation to allow for the pairing in our design.

Symptom scores for each subject on each mountain in order of ascent (after deduction for non-ascent days symptoms)

\begin{tabular}{|c|c|c|c|c|c|c|c|}
\hline \multicolumn{4}{|c|}{ Treatment group 1} & \multicolumn{4}{|c|}{ Treatment group 2} \\
\hline $\begin{array}{l}\text { Subject } \\
\text { No }\end{array}$ & Age & $\begin{array}{c}\text { Acetazolamide } \\
\text { Kilimanjaro }\end{array}$ & $\begin{array}{l}\text { Placebo } \\
\text { Mt Kenya }\end{array}$ & $\begin{array}{l}\text { Subject } \\
\text { No }\end{array}$ & Age & $\begin{array}{c}\text { Placebo } \\
\text { Kilimanjaro }\end{array}$ & $\begin{array}{c}\text { Acetazolamide } \\
\text { Mt Kenya }\end{array}$ \\
\hline $\begin{array}{r}1 \\
3 \\
5 \\
7 \\
9 \\
11 \\
13 \\
15 \\
17 \\
19 \\
21 \\
23\end{array}$ & $\begin{array}{l}20 \\
20 \\
49 \\
36 \\
17 \\
45 \\
45 \\
36 \\
45 \\
41 \\
27 \\
42(\mathrm{~F})\end{array}$ & $\begin{array}{r}7 \\
13 \\
3 \\
4 \\
5 \\
6 \\
0 \\
1 \\
3 \\
5 \\
9 \\
2\end{array}$ & $\begin{array}{c}0 \\
7 \\
3 \\
\text { missing } \\
-1 \\
-1 \\
0 \\
0 \\
0 \\
2 \\
9 \\
2 \\
2\end{array}$ & $\begin{array}{r}2 \\
4 \\
6 \\
8 \\
10 \\
12 \\
14 \\
16 \\
18 \\
20 \\
22 \\
24\end{array}$ & $\begin{array}{l}20 \\
21 \\
43 \\
23 \\
18 \\
45 \\
50 \\
36 \\
41 \\
19 \\
19 \\
24(\mathrm{~F})\end{array}$ & $\begin{array}{r}25 \\
19 \\
17 \\
7 \\
9 \\
12 \\
18 \\
12 \\
5 \\
12 \\
18 \\
17\end{array}$ & $\begin{array}{r}-1 \\
5 \\
9 \\
1 \\
3 \\
2 \\
2 \\
0 \\
4 \\
-1 \\
-2 \\
8\end{array}$ \\
\hline $\begin{array}{l}\text { Total score } \\
\text { Mean }\end{array}$ & & $\begin{array}{c}58 \\
4 \cdot 8\end{array}$ & 21.9 & & & $\begin{array}{c}171 \\
14 \cdot 3\end{array}$ & $\begin{array}{l}30 \\
2 \cdot 5\end{array}$ \\
\hline
\end{tabular}

to give a baseline score. This was subtracted from each ascent day's score, giving rise to some negative scores. The analysis uses three-day (ascent period) scores for each person, as both acute mountain sickness and acetazolamide were expected to have most effect during these periods. Each analysis started on the first night over $3000 \mathrm{~m}$ and so

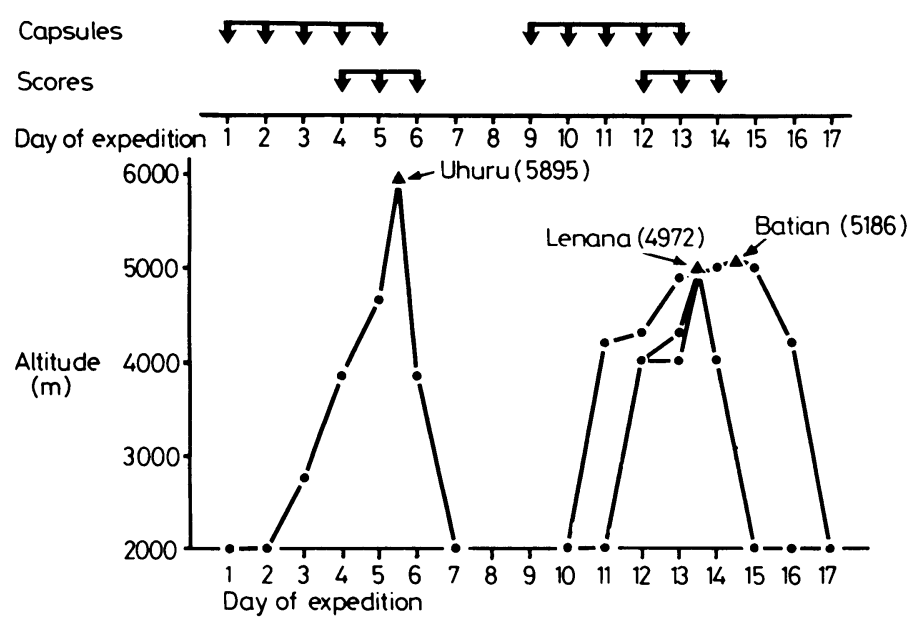

FIG 1-Expedition programme.

\section{Results}

No one left the expedition. Illness other than acute mountain sickness was trivial. Diarrhoea was reported on 11 days (five on acetazolamide and six others). Acute mountain sickness manifest as severe headache and vomiting prevented subject 24 from making the final six-hour ascent (on placebo) of the summit of Kilimanjaro. On Mt Kenya breathlessness at rest and severe inappropriate weakness prevented her from climbing (on acetazolamide) above $3500 \mathrm{~m}$. On this occasion her two tent mates (subjects 20 and 22) remained with her voluntarily; both were taking acetazolamide. As exclusion of these two subjects from statistical analysis does not alter the conclusions, they have been included. Compliance was in general excellent. On Mt Kenya subject 18 stopped his acetazolamide after taking one, saying that he felt ill, and subject 10 mislaid his acetazolamide after taking two. Subject 7 failed to complete his card on Mt Kenya. The double blind was entirely successful.

Of side effects, tingling in the extremities was reported by 7 out of 24 subjects $\left(29^{\prime \prime}(0)\right.$ on acetazolamide and three out of $24(12 \%)$ on placebo. Diuresis was not remarked on, perhaps because of concurrent changes in living conditions. Nausea was reported on the first day of taking acetazolamide by two of $24\left(8^{\prime \prime}{ }^{\circ}\right)$ (none on placebo).

With the exceptions mentioned above, planned objectives were reached by all subjects on Mt Kenya.

Fig 2 compares the altitudes reached on Kilimanjaro by subjects on acetazolamide and placebo. Those taking acetazolamide showed a striking advantage (Wilcoxon signed rank sum test $p<0.01$ ). The symptom scores of each treatment group on each mountain also show an impressive advantage for those taking acetazolamide on Kilimanjaro 
(see table). In every pair the partner on acetazolamide had the lower symptom score (Wilcoxon signed rank sum test $\mathrm{p}<0.001$ ). On $\mathrm{Mt}$ Kenya the two groups performed equally well. Those previously on placebo improved greatly on acetazolamide, while those previously on acetazolamide maintained their low scores although taking placebo. It is clear that the first treatment and ascent period had an effect on the second. The presence of this interaction was confirmed statistically using a test based on that described by Armitage and Hills $(\mathrm{p}<0.01) .{ }^{9}$

Fig 3 shows the total cross-over experience graphically. Pairs $9 / 10$ and $17 / 18$ failed to take the full course of acetazolamide. No statistically significant association was found between the ages of subjects and their scores. On Kilimanjaro there was a suggestion of a negative association among subjects on acetazolamide (Spearman rank correlation coefficient $=-0.55(0.05<p<0.1))$. The corresponding subjects on placebo, however, showed no correlation $(r=-0.04)$, and the scores on Mt Kenya showed no correlation with age.

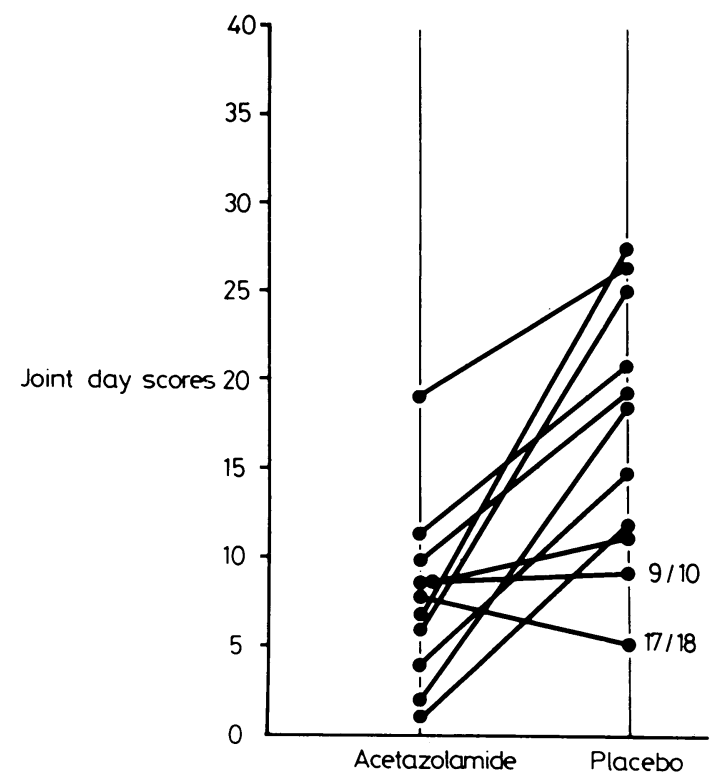

FIG 3-Joint symptom scores for each pair on each ascent. Numbers indicate pairs who failed to take full course of acetazolamide.

\section{Discussion}

The weaknesses of symptom reporting as a means of assessing acute mountain sickness are obvious but must be accepted, since there are no reliable signs of the mild form of acute mountain sickness. Advantages of our method were its simplicity and the promptness of reporting. Baseline scores helped to reduce the effect of personal differences in symptom recognition. Cooperation was excellent. The allocation of points for symptoms, while arbitrary, distinguishes clearly between the mild ones and those which indicate cerebral or pulmonary oedema.

Acetazolamide was found to be a useful prophylactic for acute mountain sickness on this expedition during rapid ascent on foot from $2500 \mathrm{~m}$ to $5000 \mathrm{~m}$. The advantage to those on acetazolamide was most evident on the ascent of the first mountain, Kilimanjaro, when conditions were ideally standardised, the whole party was walking at the same pace and with the same objective. On Mt Kenya, activity subgroups made comparisons more difficult, but assessment over three days during which altitudes and activities were similar allowed valid comparisons to be made. On this ascent, as the table shows, low scores were achieved by both treatment groups.

The slightly lower altitude of Mt Kenya and some carry-over both of physical fitness and of acclimatisation from the ascent of Kilimanjaro may have contributed to this general improvement. It may be that taking acetazolamide on the first ascent permitted trouble-free acclimatisation and training which remained of benefit on the second ascent and that the improve- ment in performance experienced by those who changed to acetazolamide for the second ascent was partly due to the drug. We can only speculate on this point, however, as we did not have enough subjects to allocate a group to placebo throughout.

Subject 24 is an important exception to the general experience of benefit from acetazolamide. Clearly no general conclusion can be drawn from her case, but it would seem to indicate that not all those liable to develop severe acute mountain sickness will be helped by acetazolamide.

It seems clear that acetazolamide is a useful prophylactic for acute mountain sickness in most cases.

We wish to thank the following for help and advice: Young Explorers Trust; Lederle Laboratories, and in particular Dr P G Brock, medical director; Birmingham Medical Research Expeditionary Society; Dr Stirling, then medical officer of health of Tanzania; and British and African members of the Scout East Africa Expedition 1980.

Correspondence should be addressed to Dr A M Kerr, Ward 6A, Royal Hospital for Sick Children, Yorkhill, Glasgow.

\section{References}

${ }^{1}$ Heath D, Williams DR. Man at high altitude. Edinburgh: Churchill Livingstone, 1977:118.

${ }^{2}$ Birmingham Medical Research Expeditionary Society Mountain Sickness Group. Acetazolamide in control of acute mountain sickness. Lancet 1981 ; : : 180-3.

${ }^{3}$ Sutton JR, Houston CS, Mansell AL, et al. Effect of acetazolamide on hypoxaemia during sleep at high altitude. $N$ Engl $f$ Med 1979;301: 1329-31.

4 Cair SM, Dunn JE. Low doses of acetazolamide to aid accommodation of men to altitude. F Appl Physiol 1966;21:1195-200.

${ }^{5}$ Forwand SA, Landowne M, Follansbee JN, et al. Effect of acetazolamide on acute mountain sickness. $N$ Engl f Med 1968;279:839-44.

- Gray GW, Bryan AC, Frayser R, et al. Control of acute mountain sickness. Aerospace Medicine 1971;42:81-4.

${ }^{7}$ Evans WO, Robinson SM, Horstmann DH, Jackson RE, Weiskopf RB. Amelioration of the symptoms of acute mountain sickness by staging and acetazolamide. Aviat Space Environ Med 1976;47:512-16.

${ }^{8}$ Hackett PH, Rennie D, Levine HD. The incidence, importance and prophylaxis of acute mountain sickness. Lancet 1976;ii:1149-54.

${ }^{9}$ Hills M, Armitage P. The two period cross-over clinical trial 1979. British fournal of Clinical Pharmacology 1979;8:7-20.

(Accepted 6 fuly 1981)

\section{OF BLEEDING.}

No operation of furgery is fo frequently neceffary as bleeding; it ought therefore to be very generally underftood. But though practifed by Midwives, Gardeners, Blackfmiths, \&c. we have reafon to believe that very few know when it is proper. Even phyficians themfelves have been fo much the dupes of theory in this article, as to render it the fubject of ridicule. It is, however, an operation of great importance, and muft, when feafonably and properly performed, be of fingular fervice to thofe in diftrefs.

BLEEDING is proper at the beginning of all inflammatory fevers, as pleurifies, peripneumonies, \&c. It is likewife proper in all topical inflammations, as thofe of the inteftines, womb, bladder, ftomach, kidnies, throat, eyes, \&c. as alfo in the afthma, fciatic pains, coughs, head-achs, rheumatifms, the apoplexy, epilepfy, and bloody flux. After falls, blows, bruifes, or any violent hurt received either externally or internally, bleeding is neceffary. It is likewife neceffary for perfons who have had the misfortune to be ftrangled, drowned, fuffocated with foul air, the fumes of metal, or the like. In a word, whenever the vital motions have been fuddenly ftopt from any caufe whatever, except in fwoonings, occafioned by mere weaknefs or hyfteric affections, it is proper to open a vein. But in all diforders proceeding from a relaxation of the folids, and an impoverifhed ftate of the blood, as dropfies, cacochymies, \&c. bleeding is improper.

(Buchan's Domestic Medicine, 1786.) 